\title{
Generation of phenylpropanoid pathway-derived volatiles in transgenic plants: rose alcohol acetyltransferase produces phenylethyl acetate and benzyl acetate in petunia flowers
}

\author{
Inna Guterman ${ }^{1}$, Tania Masci ${ }^{1}$, Xinlu Chen ${ }^{2}$, Florence Negre ${ }^{2}$, Eran Pichersky ${ }^{3}$, \\ Natalia Dudareva ${ }^{2}$, David Weiss ${ }^{1}$ and Alexander Vainstein ${ }^{1, *}$ \\ ${ }^{1}$ The Robert H. Smith Institute of Plant Sciences and Genetics in Agriculture, Faculty of Agricultural, Food \\ and Environmental Quality Sciences, The Hebrew University of Jerusalem, Rehovot 76100, Israel (*author \\ for correspondence; e-mail vain@agri.huji.ac.il); ${ }^{2}$ Department of Horticulture and Landscape Architecture, \\ Purdue University, West Lafayette, Indiana 47907-2010, USA; ${ }^{3}$ Department of Molecular, Cellular and \\ Developmental Biology, University of Michigan, Ann Arbor, Michigan 48109, USA
}

Received 12 September 2005; accepted in revised form 8 November 2005

Key words: alcohol acetyltransferases, benzenoid/phenylpropanoid pathway, flower fragrance, metabolic engineering, volatile esters

\begin{abstract}
Esters are important contributors to the aroma of numerous flowers and fruits. Acetate esters such as geranyl acetate, phenylethyl acetate and benzyl acetate are generated as a result of the action of alcohol acetyltransferases (AATs). Numerous homologous AATs from various plants have been characterized using in-vitro assays. To study the function of rose alcohol acetyltransferase (RhAAT) in planta, we generated transgenic petunia plants expressing the rose gene under the control of a CaMV-35S promoter. Although the preferred substrate of RhAAT in vitro is geraniol, in transgenic petunia flowers, it used phenylethyl alcohol and benzyl alcohol to produce the corresponding acetate esters, not generated by control flowers. The level of benzyl alcohol emitted by the flowers of different transgenic lines was ca. three times higher than that of phenylethyl alcohol, which corresponded to the ratio between the respective products, i.e. ca. three times more benzyl acetate than phenylethyl acetate. Feeding of transgenic petunia tissues with geraniol or octanol led to the production of their respective acetates, suggesting the dependence of volatile production on substrate availability.
\end{abstract}

\section{Introduction}

Flower fragrance is a composite character that is determined by a complex mixture of volatile molecules. For many years, research into flower fragrance focused on its chemical elucidation (Knudsen et al., 1993), and as a result, hundreds of compounds were identified. Recently it has been shown that these compounds are biosynthesized through a relatively small number of often interconnected metabolic pathways (Dudareva et al., 2004).
Esters constitute a major class of floral volatiles, as well as contributing to the aromas of fruits (Croteau and Karp, 1991; Knudsen and Tollsten, 1993; Gang, 2005). Volatile acetate esters such as geranyl acetate, phenylethyl acetate and benzyl acetate are generated as a result of the action of alcohol acetyltransferases (AATs) belonging to a plant-specific AAT family designated BAHD (Dudareva et al., 1998; D'Auria et al., 2002). This family was named for the first four characterized enzymes: Clarkia breweri benzyl alcohol $O$-acetyltransferase (BEAT), Gentiana triflora anthocyanin 
$O$-hydroxycinnamoyltransferase (AHCT), Dianthus caryophyllus anthranilate $N$-hydroxycinnamoyl/benzoyltransferase (HCBT), and Catharanthus roseus deacetylvindoline 4-O-acetyl-transferase (DAT) (St-Pierre and De Luca, 2000) and to date, includes several genes involved in scent and aroma formation (Gang, 2005). In-vitro characterization of these AAT homologues from various plant species revealed their broad substrate specificity towards alcohols and acyl donors (Dudareva et al., 1998; Aharoni et al., 2000; D'Auria et al., 2002; Yahyaoui et al., 2002; Shalit et al., 2003; Beekwilder et al., 2004; Boatright et al., 2004). Beekwilder et al. (2004) generated transgenic petunia constitutively expressing the strawberry fruit $A A T$ gene to analyze its function in planta. However, the transgenic flowers were not able to generate new esters or higher levels of native volatiles.

"Scent" enzymes have been identified by either first characterizing their enzymatic activity in vitro with substrates predicted to be the precursors of known products in the tissue from which they are derived (for review, see Dudareva et al., 2004), or, as is more commonly practiced today, identifying homologous sequences in genomic or EST databases, expressing a protein in a heterologous system, and then biochemically testing the enzymatic activity with a variety of substrates (Aharoni et al., 2000; Lange et al., 2000; Gang et al., 2001; Guterman et al., 2002; Chen et al., 2003; Dudareva et al., 2003; Fridman and Pichersky, 2005). In both cases, the biochemical characterization of enzymes has shown that they are often capable of reacting with several substrates. Thus, the assignment of the "correct" in-vivo substrate (or substrates) depends on the kinetic parameters of the enzyme as well as on the information about the in-vivo product(s), and is generally tentative in the absence of additional lines of evidence derived from the analysis of mutants (Fridman and Pichersky, 2005; Tholl et al., 2005). It is becoming clear that the substrate that is preferred in vitro is not necessarily the one reacted on in vivo (Negre et al., 2003; Beekwilder et al., 2004; Underwood et al., 2005).

We recently isolated a rose alcohol acetyltransferase $(R h A A T)$ responsible for the formation of geranyl acetate from geraniol and acetyl-CoA in rose flowers (Shalit et al., 2003). Biochemical characterization of the RhAAT enzyme in vitro revealed that in addition to geraniol, it exhibits activity towards a large number of alcohols, including the aromatic alcohols 2-phenylethyl alcohol and benzyl alcohol, which have been reported in petal tissue of petunia flower (Verdonk et al., 2003; Boatright et al., 2004). Here, we report the successful metabolic engineering of the benzenoid/phenylpropanoid pathway in Petunia hybrida cv. Mitchell by introducing RhAAT under a CaMV-35S promoter. Transgenic petunia flowers expressing $R h A A T$ emitted a higher level of benzyl acetate and phenylethyl acetate, indicating that the in planta availability of substrates and biochemical properties of the enzyme determine the spectrum of emitted volatiles.

\section{Materials and methods}

\section{Plant material}

Petunia W115 (cv. Mitchell) was used for the generation of transgenic plants. All plants were grown under controlled temperature $\left(27^{\circ} \mathrm{C} / 20^{\circ} \mathrm{C}\right.$ day/night) and natural photoperiod in the greenhouse.

\section{RNA gel-blot analysis}

Total RNA was extracted according to van Tunen et al. (1988). Subsequently, 5-10 $\mu \mathrm{g}$ of total RNA were fractionated in a $1 \%$ agarose gel containing formaldehyde and blotted onto Hybond $\mathrm{N}+$ membranes (Amersham-Pharmacia Biotech, Buckinghamshire, UK). The blots were hybridized in $0.263 \mathrm{M} \mathrm{Na}_{2} \mathrm{HPO}_{4}, 7 \%$ (w/v) SDS, $1 \mathrm{mM}$ EDTA and $1 \%(\mathrm{w} / \mathrm{v}) \mathrm{BSA}$ at $60{ }^{\circ} \mathrm{C}$ with ${ }^{32} \mathrm{P}$ labeled cDNA probes (Rediprime; AmershamPharmacia Biotech). The membranes were washed twice in $2 \times \mathrm{SSC}$ and $0.1 \%$ SDS at $60^{\circ} \mathrm{C}$ for $20 \mathrm{~min}$ each and exposed to X-ray film (Fuji, Tokyo, Japan) with two intensifying screens at $-70{ }^{\circ} \mathrm{C}$.

\section{DNA isolation and PCR analysis of transgenic plants}

Total DNA from petunia leaves was isolated according to Izhaki et al. (2001). PCR amplification was performed using kanamycin primers 
(Fw 5'-GAGGCTATTCGGCTATGACT-3', Rev 5'-AATCTCGTGATGGCAGGTTG-3') or $35 \mathrm{~S}$ forward and RhAAT reverse primers ( $5^{\prime}$-TCTTTA CCCTTCAAAATCTCCAA- $3^{\prime}$ ). The expected products of the PCRs were 0.8 and $0.5 \mathrm{~kb}$, respectively.

\section{Construction of a chimeric gene and plant transformation}

The pBK-CMV phagemid carrying RhAAT (GenBank accession no. AY850287) was used to amplify the gene's coding region (1374 bp). The amplified fragment was inserted into a pCd shuttle vector between the CaMV-35S promoter and OCS terminator and then the entire construct was inserted into binary vector pCGN1559 (Zuker et al., 2002). The construct was transferred via Agrobacterium tumefaciens to petunia variety W115 (cv. Mitchell) using the standard leaf-disk transformation method (Horsch et al., 1985). Transformants were regenerated as described by van Tunen et al. (1989). To confirm stable transformation, kanamycin-resistant $\mathrm{T}_{0}$ plants were analyzed by PCR.

\section{Collection of headspace volatiles and $G C-M S$ analysis}

The headspace volatiles of detached petunia flowers or leaves were trapped, eluted and concentrated as previously described (Lavid et al., 2002). The volatile compounds collected from the headspace were analyzed by GC-MS composed of a Pal autosampler (CTC Analytic, Zwingen, Switzerland), a TRACE GC 2000 equipped with an Rtx-5SIL MS (Restek, Waldbronn, Germany; i.d. $0.25 \mu \mathrm{m}, \quad 30 \mathrm{~m} \times 0.25 \mathrm{~mm}$ ) fused-silica capillary column and a TRACE DSQ quadrupole mass spectrometer (ThermoFinnigan, Hemel, UK). Helium was used as the carrier gas at a flow rate of

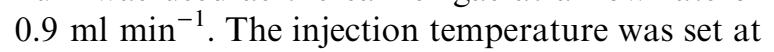
$250{ }^{\circ} \mathrm{C}$ (splitless mode), the interface at $280{ }^{\circ} \mathrm{C}$, and the ion source adjusted to $200{ }^{\circ} \mathrm{C}$. The analysis was performed under the following temperature program: $5 \mathrm{~min}$ of isothermal heating at $50{ }^{\circ} \mathrm{C}$, followed by a $5{ }^{\circ} \mathrm{C} \mathrm{min}^{-1}$ oven temperature ramp to $260{ }^{\circ} \mathrm{C}$, and finally increasing from 250 to $280^{\circ} \mathrm{C}$ at $10^{\circ} \mathrm{C} \mathrm{min}^{-1}$. The detector temperature was $280^{\circ} \mathrm{C}$. The system was equilibrated for $1 \mathrm{~min}$ at $70{ }^{\circ} \mathrm{C}$ before injection of the next sample. Mass spectra were recorded at $2 \mathrm{scan} \mathrm{s} \mathrm{s}^{-1}$ with a scanning range of 40-450 mass-to-charge ratio, and an electron energy of $70 \mathrm{eV}$. Compounds were tentatively identified (>95\% match) based on the NIST/EPA/NIH Mass Spectral Library (Data Version: NIST 05, Software Version 2.0d) using the XCALIBUR v1.3 program (ThermoFinnigan) library. Further identification of major compounds was based on a comparison of mass spectra and retention times with those of authentic compounds analyzed under similar conditions. For quantitative analyses, $10 \mu \mathrm{g} \mathrm{ml}^{-1}$ ethyl myristate was used as an internal standard (Lavid et al., 2002; Shalit et al., 2003).

\section{Feeding experiments}

Detached petunia stem sections with three to four leaves and flowers were placed in $20 \mathrm{ml}$ of feeding solution for $16 \mathrm{~h}$ at $25^{\circ} \mathrm{C}$. After incubation, flowers or leaves were detached from the stems and used for volatile collection. The feeding solutions contained either $100 \mathrm{ppm}(0.56 \mathrm{mM})$ geraniol (Sigma-Aldrich, St. Louis, MO) or $100 \mathrm{ppm}(0.63 \mathrm{mM})$ 1-octanol (Sigma-Aldrich).

\section{Partial purification of RhAAT recombinant enzyme} and determination of kinetic properties

Recombinant E. coli BL21 (DE3) bacteria were obtained and grown as described by Shalit et al. (2003). After centrifugation, cells were resuspended in buffer A [3:1 (v/w) buffer:cells] containing $50 \mathrm{mM}$ Bis-Tris- $\mathrm{HCl} \mathrm{pH} 6.9,10 \%$ glycerol and $10 \mathrm{mM} \beta$-mercaptoethanol. Resuspended cells were broken by French press (three passes at $1200 \mathrm{psi}$ ), and the cell debris was removed by centrifugation $(30 \mathrm{~min}$ at $24,000 \times \mathrm{g}$ ). The supernatant was incubated with $1 \%(\mathrm{w} / \mathrm{v})$ protamine sulfate for $30 \mathrm{~min}$ at $4{ }^{\circ} \mathrm{C}$. After centrifugation (30 min at $24,000 \times g$ ), the supernatant was dialyzed against 21 of buffer A overnight at $4{ }^{\circ} \mathrm{C}$. RhAAT protein was purified using a weak anionexchange DEAE-cellulose column followed by Mono-Q anion-exchange and size-exclusion chromatographies.

RhAAT protein was loaded onto a DEAEcellulose column (10 $\mathrm{ml}$ of DE53, Whatman, NJ) preequilibrated with buffer $\mathrm{A}$ at a flow rate of about $1 \mathrm{ml} \mathrm{min}{ }^{-1}$. After washing off unabsorbed material from the column with $60 \mathrm{ml}$ of buffer $\mathrm{A}$, 
RhAAT was eluted with a linear gradient $(60 \mathrm{ml})$ from 0 to $400 \mathrm{mM} \mathrm{KCl}$ in buffer A. Fractions $(3 \mathrm{ml})$ were collected and assayed for AAT activity with geraniol and acetyl-CoA as substrates as described previously (Shalit et al., 2003). Fractions with the highest AAT activity in the $260-310 \mathrm{mM}$ $\mathrm{KCl}$ range were pooled (total of $9 \mathrm{ml}$ ), dialyzed against buffer $\mathrm{A}$, and subjected to ion-exchange chromatography on a Mono-Q column (gel bed volume $1 \mathrm{ml}$ ) (Amersham Biosciences, Piscataway, $\mathrm{NJ})$ using the FPLC system. RhAAT protein was eluted from the column at $360-400 \mathrm{mM} \mathrm{KCl}$ using a $10 \mathrm{ml}$ linear $(0-400 \mathrm{mM})$ gradient of $\mathrm{KCl}$ in

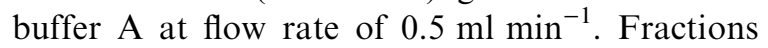
with the highest AAT activity (total of $2 \mathrm{ml}$ ) were pooled and subjected to size-exclusion chromatography (Superdex 200, $16 \mathrm{~mm} \times 60 \mathrm{~cm}$ ). Fractions of $2 \mathrm{ml}$ were collected at a flow rate of $1 \mathrm{ml} \mathrm{min}^{-1}$ and analyzed for AAT activity. Fractions exhibiting the highest activity were examined by SDSPAGE followed by Coomassie Brilliant Blue staining of the gel.

For kinetics analysis, an appropriate enzyme concentration was chosen so that the reaction velocity was proportional to the enzyme concentration and was linear with respect to incubation time for at least $30 \mathrm{~min}$. Protein concentrations were determined by the Bradford method (Bradford, 1976) using the Bio-Rad protein reagent and bovine serum albumin as a standard. Enzyme assays were performed as described previously (Shalit et al., 2003). Apparent $K_{\mathrm{m}}$ values for one substrate (geraniol, benzyl alcohol, phenyl ethanol or acetyl-CoA) were determined at saturating concentrations of the co-substrate. Kinetic data were evaluated using Lineweaver-Burk plots.

\section{Results}

Emission of volatiles by transgenic petunia flowers expressing the RhAAT gene

After initial selection of transgenic petunia carrying the CaMV-35S promoter-RhAAT construct on kanamycin and screening the plants by PCR for the presence of the foreign DNA (data not shown), the expression of $R h A A T$ in flowers of independent transformants (Figure 1) was examined by RNA gel-blot analysis. Transgenic plants expressed RhAAT at different levels, while no signal was

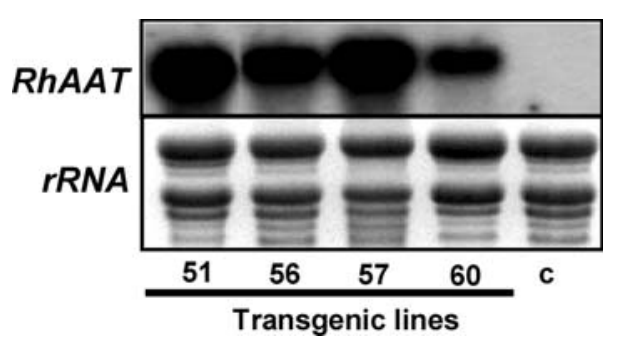

Figure 1. Molecular analyses of transgenic petunia plants expressing RhAAT. Expression of RhAAT driven by a CaMV-35S promoter in flowers of independent transgenic lines $(51,56,57,60)$ and control (C) flowers was analyzed by RNA blot. Ethidium-bromide staining of rRNA is shown.

detected in control, non-transgenic plants. The transgenic plants did not appear to be different from control plants with respect to overall morphology, time to flowering, growth rate, or flower architecture, development, or pigmentation.

Headspace analysis of non-transgenic petunia flowers showed the emission of benzaldehyde, benzyl alcohol and 2-phenylethyl alcohol, as well as of the esters benzyl acetate and methyl benzoate, similar to the previously published volatile profile of petunia flowers (Verdonk et al., 2003). Initial headspace analyses of flowers from four independent transgenic petunia lines revealed that they emit much higher levels of benzyl acetate and phenylethyl acetate, as compared to control flowers (Figure 2). Quantitative headspace analyses confirmed that all of these lines emit 5 (in line T51) to 10 (in line T60) times higher levels of these two acetate esters compared to control flowers (Figure 3). The level of emitted phenylethyl alcohol, the alcohol precursor of phenylethyl acetate, was elevated in transgenic plants (Figure 3B), whereas the level of emitted benzyl alcohol, the alcohol precursor of benzyl acetate, was lower (line T51) or not significantly different (other lines) from that measured in control, non-transgenic plants (Figure 3A).

\section{Volatile production by RhAAT-transgenic petunia flowers and leaves fed with precursors}

Kinetics parameters of recombinant RhAAT in vitro with geraniol, phenylethyl and benzyl alcohols, and acetyl-CoA were determined (Table 1) since in the previous study, $K_{\mathrm{m}}$ values for phenylethyl alcohol and benzyl alcohol were not obtained (Shalit et al., 2003). RhAAT $K_{\mathrm{m}}$ values for benzyl alcohol and phenyl ethanol using 


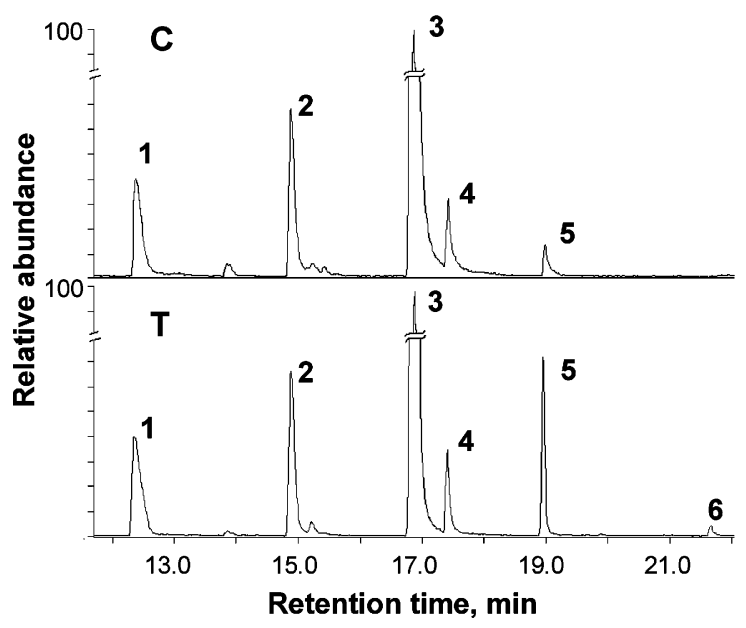

Figure 2. GC-MS headspace analysis of volatile compounds, emitted from detached flowers of RhAAT-transgenic (T, line 56) and control, non-transgenic (C) petunia plants. A representative GC chromatogram is presented. 1 - benzaldehyde, 2 - benzyl alcohol, 3 - methyl benzoate, 4 - phenylethyl alcohol, 5 - benzyl acetate, 6 - phenylethyl acetate. In-vivo production of novel acetates was assayed in detached flowers for $24 \mathrm{~h}$.

acetyl-CoA as an acyl donor were 5.5 and 12 times higher (15.4 and $34.2 \mathrm{mM}$ ), respectively, than with geraniol. The apparent catalytic efficiency of the recombinant RhAAT, in vitro, for alcohol substrates with acetyl-CoA was $155 \mathrm{~s}^{-1} \mathrm{M}^{-1}$ for geraniol, $21 \mathrm{~s}^{-1} \mathrm{M}^{-1}$ for phenyl ethanol and $8 \mathrm{~s}^{-1} \mathrm{M}^{-1}$ for benzyl alcohol (Table 1), indicating that, in vitro, geraniol is the preferred substrate. The $K_{\mathrm{m}}$ obtained for acetyl-CoA was comparable for the three different alcohols (47.38-134.33 $\mu \mathrm{M})$; however, catalytic efficiency was higher when geraniol was used as the alcohol substrate (Table 1).

To test whether RhAAT in transgenic plants could use geraniol, the preferred substrate in the in vitro assay, we analyzed the headspace of detached flowers following feeding with geraniol. Flowers with ca. $10 \mathrm{~cm}$ stems were incubated in a $10 \mathrm{mM}$ solution of geraniol for $2 \mathrm{~h}$ at $22{ }^{\circ} \mathrm{C}$. Flowers were then detached from the stems and headspace analyses of the emitted volatiles were performed. Transgenic petunia flowers, fed with geraniol, produced and emitted geranyl acetate. The flowers of control petunia plants did not generate this acetate ester following feeding with geraniol (Figure 4B). The production of geranylacetate was also observed in detached leaves of transgenic but not control petunias fed with geraniol (Figure 4A).

We also tested the ability of recombinant RhAAT to acetylate 1-octanol, an additional

Table 1. Kinetic parameters of RhAAT protein.

\begin{tabular}{lcccc}
\hline & $K_{\mathrm{m}}(\mu \mathrm{M})$ & $V_{\max }(\mathrm{pkat} / \mathrm{mg})$ & $K_{\text {cat }}^{\mathrm{e}}\left(\mathrm{s}^{-1}\right)$ & $K_{\text {cat }} / K_{\mathrm{m}}^{\mathrm{f}}\left(\mathrm{s}^{-1} \mathrm{M}^{-1}\right)$ \\
\hline Acetyl-CoA $^{\mathrm{a}}$ & $47.38 \pm 7.22$ & $5475 \pm 327$ & $0.28 \pm 0.02$ & $6148 \pm 523$ \\
Acetyl-CoA $^{\mathrm{b}}$ & $86.38 \pm 7.85$ & $2473 \pm 77$ & $0.128 \pm 0.004$ & $1502 \pm 99$ \\
Acetyl-CoA $^{\mathrm{c}}$ & $134.33 \pm 10.46$ & $10414 \pm 314$ & $0.54 \pm 0.02$ & $4051 \pm 225$ \\
Geraniol $^{\mathrm{d}}$ & $2783 \pm 460$ & $8222 \pm 1039$ & $0.43 \pm 0.05$ & $155 \pm 6$ \\
Benzyl alcohol $^{\mathrm{d}}$ & $15403 \pm 774$ & $2294 \pm 76$ & $0.119 \pm 0.004$ & $8 \pm 0.2$ \\
Phenyl ethanol $^{\mathrm{d}}$ & $34213 \pm 3714$ & $13988 \pm 1171$ & $0.72 \pm 0.06$ & $21 \pm 0.5$ \\
\hline
\end{tabular}

${ }^{a}$ With $5 \mathrm{mM}$ geraniol.

${ }^{\mathrm{b}}$ With $50 \mathrm{mM}$ benzyl alcohol.

${ }^{\mathrm{c}}$ With $40 \mathrm{mM}$ phenyl ethanol.

${ }^{\mathrm{d}}$ Alcohols were assayed using saturating concentrations of acetyl-CoA (180 $\mu \mathrm{M}$ for geraniol, $480 \mu \mathrm{M}$ for benzyl alcohol and phenyl ethanol).

${ }^{\mathrm{e}} K_{\text {cat }}$, turnover number.

${ }^{\mathrm{f}} K_{\text {cat }} / K_{\mathrm{m}}$, catalytic efficiency.

Results are an average of three independent experiments \pm a $95 \%$ confidence interval of the mean. 

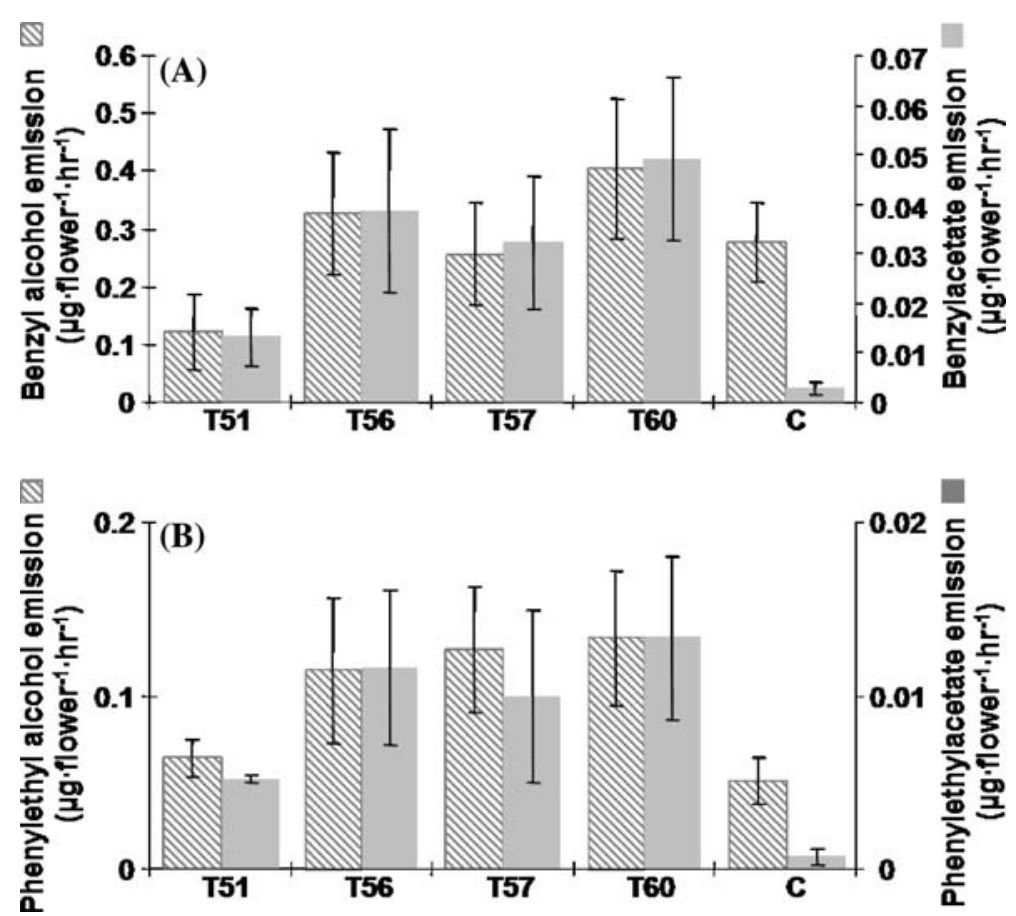

Figure 3. Emission of benzyl alcohol and benzyl acetate (A) and phenylethanol and phenylethyl acetate (B) from RhAAT-transgenic petunia flowers. Quantitative headspace GC-MS analyses of benzyl acetate and phenylethyl acetate in transgenic (T) petunia (independent lines 51,56,57,60) and control (C) flowers were performed using ethyl myristate as the standard. Flowers one day after anthesis were used and means of five replicates $\pm \mathrm{SE}$ are presented.

potential substrate (Shalit et al., 2003). Similar to geraniol, following feeding, octanol was used as a substrate in planta by transgenic petunia flowers to produce octylacetate, but control flowers did not emit any octylacetate (Figure 5B). The production of octylacetate was also observed in detached leaves of transgenic but not control petunias fed with octanol (Figure 5A).

\section{Discussion}

Acetate esters represent one of the major groups of volatiles determining the scent of flowers and aroma of fruits (Knudsen and Tollsten, 1993). These volatile esters are synthesized from alcohols, generated via various metabolic pathways, by AATs belonging to a unique plant protein family of BAHD acyltransferases (Dudareva et al., 1998; D'Auria et al., 2002). Numerous genes encoding BAHD AATs have been isolated and biochemically characterized using in-vitro systems (Dudareva et al., 1998; Aharoni et al., 2000; D'Auria et al., 2002; Yahyaoui et al., 2002; Shalit et al.,
2003; Beekwilder et al., 2004; Boatright et al., 2004). It has been shown that each of these enzymes can convert various alcohols, and typically the prediction of their in-vivo activity is based on the highest substrate affinity in vitro. For example, the rose RhAAT was shown to be able to use geraniol, citronellol, nerol, octanol, hexanol, phenylethyl alcohol and benzyl alcohol in vitro (Shalit et al., 2003). As the enzyme showed the highest preference to geraniol and citronellol, and rose flowers emit geranyl acetate, the protein was designated geraniol/citronellol acetyltransferase. Similarly, an enzyme found in the benzyl-acetateemitting Clarkia breweri flowers that exhibited the highest activity with benzyl alcohol was designated benzyl alcohol acetyltransferase (BEAT), although it could also acetylate cinnamyl alcohol, 2-naphthalene ethanol and phenyl ethanol, albeit at lower rates (Dudareva et al., 1998).

To evaluate the function of AATs in planta, Beekwilder et al. (2004) recently generated transgenic $P$. hybrida cv. Mitchell expressing strawberry SAAT, which exhibited its highest activity in vitro with geraniol among the substrates tested, but 

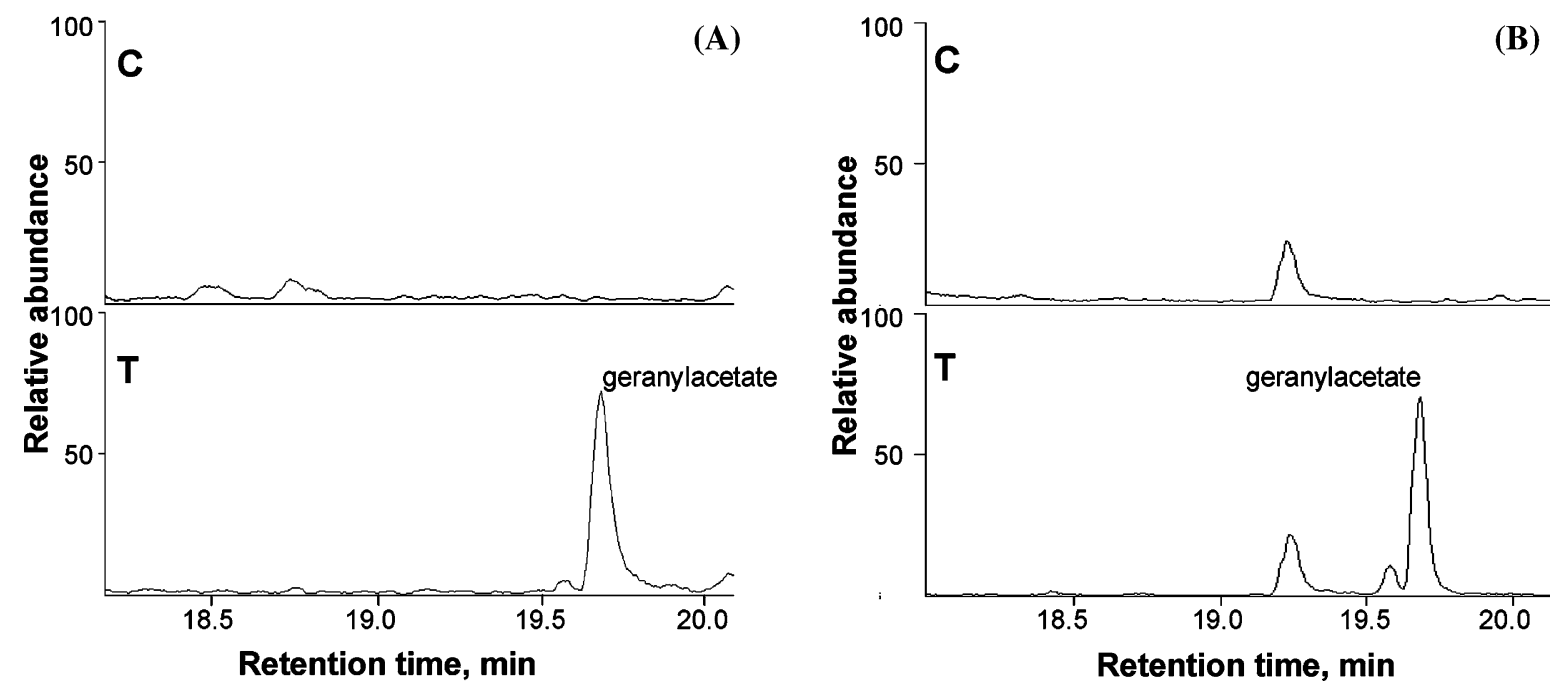

Figure 4. Production of geranyl acetate by RhAAT-transgenic petunia following feeding with geraniol. GC-MS headspace analysis of volatile compounds emitted from leaves (A) and flowers (B) of RhAAT-transgenic (T, line 56) and control, non-transgenic (C) petunia plants. Stems with leaves and flowers were placed in feeding solution containing geraniol for $16 \mathrm{~h}$ at $25^{\circ} \mathrm{C}$. After incubation, flowers or leaves were detached from the stems and used for collecting volatiles. The peak at 19.2 min represents eugenol.

whose substrate in the strawberry fruit was not known. Petunia flowers do not synthesize geraniol but produce 2-phenylethyl alcohol and benzyl alcohol, which are very poor substrates for SAAT in vitro $(7 \%$ and $3 \%$ of SAAT activity with geraniol, respectively) (Beekwilder et al., 2004). These transgenic petunia flowers were not able to generate any new esters. In contrast, the transgenic
P. hybrida cv. Mitchell, expressing the rose RhAAT generated in this study, emitted much higher levels of benzyl acetate as well as phenylethyl acetate, demonstrating the possibility of direct metabolic engineering of phenylpropanoid pathway-derived volatiles.

RhAAT is the closest homologue of SAAT in the database and the substrate specificity of these

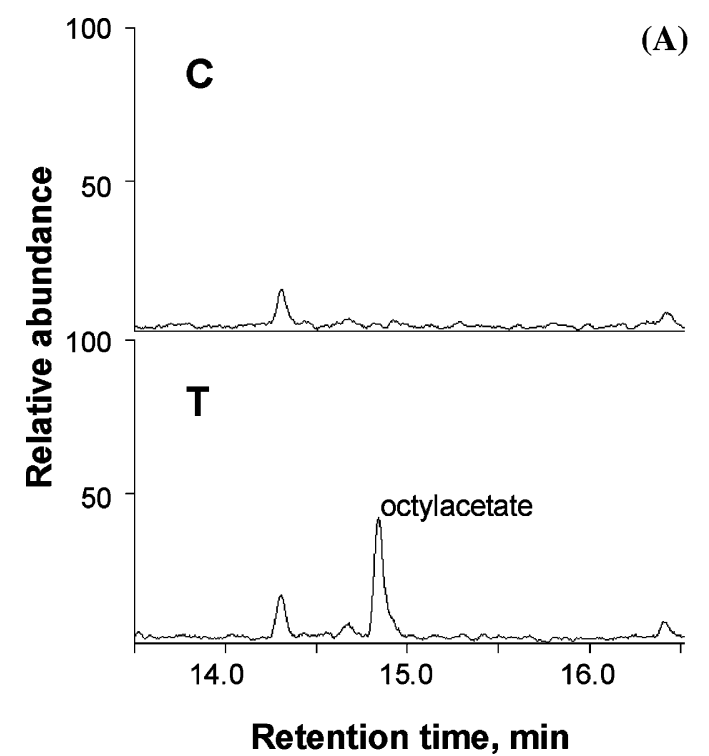

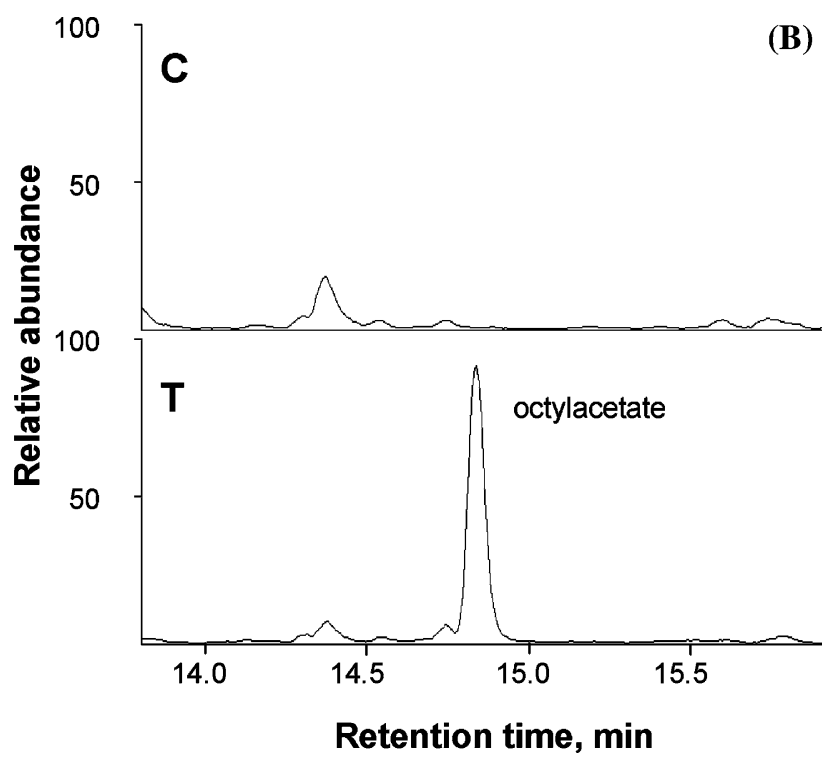

Figure 5. Production of octylacetate by RhAAT-transgenic petunia following feeding with octanol. GC-MS headspace analysis of volatile compounds emitted from leaves (A) and flowers (B) of RhAAT-transgenic ( $\mathrm{T}$, line 56) and control, non-transgenic (C) petunia plants. Stems with leaves and flowers were placed in feeding solution containing octanol for $16 \mathrm{~h}$ at $25^{\circ} \mathrm{C}$. After incubation, flowers or leaves were detached from the stems and used for collecting volatiles. The peak at 14.4 min could not be identified. 
two enzymes is also very similar in vitro. Furthermore, petunia with the same genetic background was used for the activity analyses of both rose and strawberry AATs in planta. The differences obtained in planta may be due to protein-sequence divergence, which may affect the in planta enzyme affinity and catalytic efficiency toward the substrates, i.e. phenylethyl alcohol and benzyl alcohol, despite the similar enzyme-substrate preferences in vitro. Within the flower tissue, these enzymes have to compete with the native benzoyl-CoA:benzyl alcohol/phenylethanol benzoyltransferase (BPBT) (Boatright et al., 2004) for alcohol substrates. Moreover, BPBT can also potentially use acetyl-CoA. Thus, the observed levels of volatileester emission reflect the relative protein levels of introduced RhAAT and the endogenous BPBT, their maximal velocities, and substrate affinities for alcohol substrates and acyl donors.

Surprisingly, three out of the four transgenic petunia lines examined emitted higher levels of phenylethanol (Figure 3B), while the level of benzyl alcohol was lower (one transgenic line) or relatively unaffected (Figure 3A). Biosynthesis of these alcohols follows two different routes. The first step in the synthesis of benzyl alcohol is the conversion of L-phenylalanine to trans-cinnamic acid by phenylalanine ammonia lyase (PAL), whereas this step is not required for the formation of phenylethanol (Boatright et al., 2004). The reason for the higher levels of phenylethanol in transgenic lines is currently unknown. However, these results reflect the complexity of the mechanisms involved in the regulation of biochemical pathways leading to secondary-metabolite formation.

Recent advances in the isolation of scent biosynthetic genes have provided the basis and created the opportunity for the biotechnological manipulation of floral scent. In the last few years, several attempts have been made to metabolically engineer floral scent using not only the genes responsible for the synthesis of volatile compounds, but also those involved in the secondary modification of scent compounds, as well as transcriptional regulators (Vainstein et al., 2001; Dudareva et al., 2004; Lucker et al., 2004; Dudareva and Negre, 2005; Verdonk et al., 2005). The information generated from these studies revealed additional, unexpected problems that can be encountered in the genetic engineering of flower fragrance: modification of the scent compound into a non-volatile form, e.g. by glycosylation, masking by other volatiles, or the emitted amount being insufficient for olfactory detection by humans (summarized in Dudareva and Negre, 2005). The results presented here demonstrate the possibility of engineering volatile phenylpropanoid esters using an AAT with broad substrate specificity. Our data clearly show that the in-vivo function of such an enzyme is not only determined by its in-vitro substrate specificity, but is also strongly dependent on the level of available substrate. Detailed analyses of levels, availability and types of potential substrates and detailed biochemical characterization of enzyme activity towards various substrates are hence a prerequisite for in planta modulation of metabolic flow for floral-scent modification.

\section{Acknowledgements}

This work was funded by grant number 812 0393-04 from the Chief Scientist of the Israel Ministry of Agriculture and Rural Development to $\mathrm{AV}$ and $\mathrm{DW}$, by research grant number US-3437-03 from BARD to ND, AV, DW and EP and by the Hebrew University Intramural Research Fund Basic Project Award to AV and DW.

\section{References}

Aharoni, A., Keizer, L.C.P., Bouwmeester, H.J., Sun, Z.K., Alvarez-Huerta, M., Verhoeven, H.A., Blaas, J., van Houwelingen, A.M.M.L., De Vos, R.C.H., van der Voet, H., Jansen, R.C., Guis, M., Mol, J., Davis, R.W., Schena, M., van Tunen, A.J. and O'Connell, A. 2000. Identification of the SAAT gene involved in strawberry flavor biogenesis by use of DNA microarrays. Plant Cell 12: 647-661.

Beekwilder, J., Alvarez-Huerta, M., Neef, E., Verstappen, F.W.A., Bouwmeester, H.J. and Aharoni, A. 2004. Functional characterization of enzymes forming volatile esters from strawberry and banana. Plant Physiol. 135: 18651878 .

Boatright, J., Negre, F., Chen, X., Kish, C.M., Wood, B., Peel., G., Orlova., I., Gang, D., Rhodes, D. and Dudareva, N. 2004. Understanding in vivo benzenoid metabolism in petunia petal tissue. Plant Physiol. 135: 1993-2011.

Bradford, M.M. 1976. A rapid and sensitive method for the quantitation of microgram quantities of protein utilizing the principle of protein-dye binding. Anal. Biochem. 72: 248254. 
Chen, F., Tholl, D., D'Auria, J.C., Farooq, A., Pichersky, E. and Gershenzon, J. 2003. Biosynthesis and emission of terpenoid volatiles from Arabidopsis flowers. Plant Cell 15: 481-494.

Croteau, R. and Karp, F. 1991. Origin of natural odorants. In: P. D. Muller Lamparsky (Ed.), Perfume: Art, Science and Technology, Elsevier Applied Sciences, New York, pp. 101126.

D'Auria, J.C., Chen, F. and Pichersky, E 2002. Characterization of an acyltransferase capable of synthesizing benzylbenzoate and other volatile esters in flowers and damaged leaves of Clarkia brewer. Plant Physiol. 130: 466-476.

Dudareva, N., D'Auria, J.C., Nam, K.H., Raguso, R.A. and Pichersky, E. 1998. Acetyl-CoA:benzylalcohol acetyltransferase - an enzyme involved in floral scent production in Clarkia breweri. Plant J. 14: 297-304.

Dudareva, N., Martin, D., Kish, C.M., Kolosova, N., Gorenstein, N., Faldt, J., Miller, B. and Bohlmann, J. 2003. (E)$\{\beta\}$-ocimene and myrcene synthase genes of floral scent biosynthesis in snapdragon: function and expression of three terpene synthase genes of a new terpene synthase subfamily. Plant Cell 15: 1227-1241.

Dudareva, N. and Negre, F. 2005. Practical applications of research into the regulation of plant volatile emission. Curr. Opin. Plant Biol. 8: 113-118.

Dudareva, N., Pichersky, E. and Gershenzon, J. 2004. Biochemistry of plant volatiles. Plant Physiol. 135: 1893-1902.

Fridman, E. and Pichersky, E. 2005. Metabolomics, genomics, proteomics, and the identification of enzymes and their substrates and products. Curr. Opin. Plant Biol. 8: 242-248.

Gang, D. 2005. Evolution of flavors and scents. Ann. Rev. Plant Biol. 56: 301-325.

Gang, D., Wang, J., Dudareva, N., Hee Nam, K., Simon, J.E., Lewinsohn, E. and Pichersky, E. 2001. An investigation of the storage and biosynthesis of phenylpropenes in sweet basil. Plant Physiol. 125: 539-555.

Guterman, I., Shalit, M., Menda, N., Piestun, D., Dafny-Yelin, M., Shalev, G., Davydov, O., Ovadis, M., Emanuel, M., Wang, J., Adam, Z., Pichersky, E., Lewinsohn, E., Zamir, D., Vainstein, A. and Weiss, D. 2002. Rose scent: genomic approach to discover novel floral fragrance-related genes. Plant Cell 14: 2325-2338.

Horsch, R.B., Fry, J.E., Hofman, N.L., Eichholz, D., Rogers, S.G. and Fraley, R.T. 1985. A simple and general method for transferring genes into plants. Science 227: 1229-1231.

Izhaki, A., Swain, S.M., Tseng, T., Borochov, A., Olszewski, N.E. and Weiss, D. 2001. The role of SPY and SPY's TPR domains in the regulation of gibberellin action throughout the life cycle of Petunia hybrida plants. Plant J. 28: 181-190.

Knudsen, J.T. and Tollsten, L. 1993. Trends in floral scent chemistry in pollination syndromes: floral scent composition in moth-pollinated taxa. Bot. J. Linn. Soc. 113: 263-284.

Knudsen, J.T., Tollesten, L. and Bergstrom, G.L. 1993. Floral scent - a checklist of volatile compounds isolated by headspace techniques. Phytochemistry 33: 252-280.

Lange, B.M., Wildung, M.R., Stauber, E.J., Sanchez, C., Pouchnik, D. and Croteau, R 2000. Probing essential oil biosynthesis and secretion by functional evaluation of expressed sequence tags from mint glandular trichomes. Proc. Natl. Acad. Sci. USA 97: 2934-2939.

Lavid, N., Wang, J., Shalit, M., Guterman, I., Bar, E., Beuerle, T., Menda, N., Shafir, S., Zamir, D., Adam, Z., Vainstein, A., Weiss, D., Pichersky, E. and Lewinsohn, E. 2002.
$O$-methyltransferases involved in the biosynthesis of volatile phenolic derivatives in rose petals. Plant Physiol. 129: 18991907.

Lucker, J, Schwab, W., van Hautum, B., Blaas, J., van der Plas, L.H.W., Bouwmeester, H.J. and Verhoeven, H.A. 2004. Increased and altered fragrance of tobacco plants after metabolic engineering using three monoterpene synthases from lemon. Plant Physiol. 134: 510-519.

Negre, F., Kish, C.M., Boatright, J., Underwood, B., Shibuya, K., Wagner, C., Clark, D.G. and Dudareva, N. 2003. Regulation of methylbenzoate emission after pollination in snapdragon and petunia flowers. Plant Cell 15: 2992-3006.

Shalit, M., Guterman, I., Volpin, H., Bar, E., Tamari, T., Menda, N., Adam, Z., Zamir, D., Vainstein, A., Weiss, D., Pichersky, E. and Lewinsohn, E. 2003. Volatile ester formation in roses: identification of an acetyl-CoA:geraniol acetyltransferase in developing rose petals. Plant Physiol. 131: 1868-1876.

St-Pierre, B. and De Luca, V. 2000. Evolution of acyltransferase genes: origin and diversification of the BAHD superfamily of acyltransferases involved in secondary metabolism. In: R.I. John, T. Romeo, L. Varin and V. LucaDe (Eds.), Recent Advances in Phytochemistry Evolution of Metabolic Pathways. Elsevier Science Publishing, Oxford, pp. 285-315.

Tholl, D., Chen, F., Petri, J., Gershenzon, J. and Pichersky, E. 2005. Two sesquiterpene synthases are responsible for the complex mixture of sesquiterpenes emitted from Arabidopsis flowers. Plant J 42: 757-771.

Underwood, B.A., Tieman, D.M., Shibuya, K., Dexter, R.J., Loucas, H.M., Simkin, A.J., Sims, C.A., Schmelz, E.A., Klee, H.J. and Clark, D.G. 2005. Ethylene-regulated floral volatile synthesis in petunia corollas. Plant Physiol. 138: 255-266.

Vainstein, A., Lewinsohn, E., Pichersky, E. and Weiss, D. 2001. Floral fragrance New inroads into an old commodity. Plant Physiol. 127: 1383-1389.

van Tunen, A.J., Koes, R.E., Splet, C.E., van der Krol, A.R., Stuitje, A.R. and Mol, J.N.M. 1988. Cloning of the chalcone flavanone isomerase genes from Petunia hybrida: coordinate, light-regulated and differential expression of flavonoid genes. EMBO J. 7: 1257-1263.

van Tunen, A.J., Mur, L.A., Brouns, G.S., Rienstra, J.D., Koes, R.E. and Mol, J.N.M. 1989. Pollen- and antherspecific chi promoters from Petunia: tandem promoter regulation of the chiA gene. Plant Cell 2: 393-401.

Verdonk, J.C., Haring, M.A., van Tunen, A.J. and Schuurink, R.C. 2005. ODORANT1 regulates fragrance biosynthesis in petunia flowers. Plant Cell 17: 1612-1624.

Verdonk, J.C., de Ric Vos, C.H., Verhoeven, H.A, Haring, M.A., van Tunen, A.J. and Schuurink, R.C. 2003. Regulation of floral scent production in petunia revealed by targeted metabolomics. Phytochemistry 62: 997-1008.

Yahyaoui, F.E., Wongs-Aree, C., Latche, A., Hackett, R., Grierson, D. and Pech, J.C. 2002. Molecular and biochemical characteristics of a gene encoding an alcohol acyltransferase involved in the generation of aroma volatile esters during melon ripening. Eur. J. Biochem. 269: 23592366.

Zuker, A., Tzfira, T., Ben-Meir, H., Ovadis, M., Shklarman, E., Itzhaki, H., Forkmann, G., Martens, S., Neta-Sharir, I., Weiss, D. and Vainstein, A. 2002. Modification of flower color and fragrance by antisense suppression of the flavanone 3-hydroxylase gene. Mol. Breed. 9: 33-41. 